\title{
COMPARATIVE STUDY OF THE EFFICACY OF MIFEPRISTONE WITH VAGINAL MISOPROSTOL AND VAGINAL MISOPROSTOL ALONE FOR FIRST TRIMESTER ABORTION
}

\author{
Hemalatha Kulandai Raj1, Subburathinam Rajaragupathy²
}

${ }^{1}$ Associate Professor, Department of Obstetrics and Gynaecology, Government Thoothukudi Medical College, Thoothukudi. ${ }^{2}$ HOD Incharge, Department of Obstetrics and Gynaecology, Government Thoothukudi Medical College, Thoothukudi.

\begin{abstract}
\section{OBJECTIVES}

To assess the efficacy of mifepristone with misoprostol combination in first trimester abortion. To compare this combination with vaginal misoprostol alone for the first trimester MTP. To compare the various parameters involved in MTP in both the methods and assess the most suitable method for first trimester MTP.
\end{abstract}

\section{METHODS}

An interventional prospective study conducted in the Department of Obstetrics and Gynaecology at Government Thoothukudi Medical College, Thoothukudi, during 2013-2015. During this study, 125 patients who attended the family planning clinic requesting first trimester termination of pregnancy were selected based on the inclusion, exclusion criteria. Out of 125 patients, 100 were randomly assigned to vaginal misoprostol group and 25 to mifepristone with misoprostol group. The study was approved by the hospital ethical committee.

\section{RESULTS}

On analysing both the methods had less induction abortion interval, but 93\% of abortions occurred within 4 hours of administration in mifepristone and vaginal misoprostol.

\section{CONCLUSION}

Thus, the combined regimen has more rate of complete abortion with less induction abortion interval than when misoprostol alone was used.

\section{KEYWORDS}

Mifepristone, Misoprostol Combination, First Trimester Abortion.

HOW TO CITE THIS ARTICLE: Raj HK, Rajaragupathy S. Comparative study of the efficacy of mifepristone with vaginal misoprostol and vaginal misoprostol alone for first trimester abortion. J. Evolution Med. Dent. Sci. 2016;5(63):4476-4479, DOI: $10.14260 /$ jemds/2016/1020

\section{INTRODUCTION}

In a developing country like India can MTP have an impact on reduction of maternal mortality and morbidity? Yes, it will through promoting safe abortion.

Globally, out of 210 million pregnancies that occur each year, about 46 million (22\%) end in induced abortion of which 20 million is estimated to be unsafe.(1) Majority are likely to have at least one abortion by the time they are 45 years. It is unfortunate and disheartening to note that in spite of liberalised abortion rules there is still one unsafe abortion for every 7 live birth.

In India, unsafe abortions contribute to $8 \%$ of maternal death. In India, about 10 women die due to unsafe abortions each day though abortion has been legal since 1971, which came into force from April 1, 1972, (the act was again revised in 1975). In India, the abortion scenario is that 3.1 lakh legal abortions are being performed every year with an abortion rate of 23/1000 pregnancy, 4.6 million illegal abortions are being performed every year with an illegal abortion rate if

Financial or Other, Competing Interest: None.

Submission 14-07-2016, Peer Review 27-07-2016,

Acceptance 29-07-2016, Published 08-08-2016.

Corresponding Author:

Dr. Hemalatha Kulandai Raj,

Associate Professor

Department of Obstetrics and Gynaecology,

Government Thoothukudi Medical College,

Thoothukudi.

E-mail: hemasreerithik@gmail.com

DOI: $10.14260 /$ jemds/2016/1020
$130-200 / 1000$ pregnancy. Maternal mortality due to legal abortion-0.7/100,000 and due to criminal abortion$500 / 100,000$. Complications of unsafe abortions may lead to sequelae such as infertility, chronic PID, TO mass, etc. Hence, safe and simple abortion procedures and techniques for early-induced abortion are the need of the hour.(2)

The methods available for first trimester abortion are menstrual regulation, manual/electrical vacuum aspiration, dilation and curettage, laminaria tent, and prostaglandins for cervical dilation, and medical methods. ${ }^{(3)}$

Although, various methods are available, each has its own complications like, excessive bleeding, uterine perforation, syncopal attacks, shock, infection, incompetence of os, cervical stenosis, Asherman syndrome, chronic pelvic inflammatory disease, and infertility.(4) Medical methods are safe, efficient, simple, and results usually in complete abortion.

Of the various medical methods, mifepristone with misoprostol have largely replaced other procedures. Both mifepristone with misoprostol have been used singly in various doses and also in combination dosage scheduled to be superior and safer than others. (5)

This study is done to compare the efficacy, complication, and complete abortion rate of mifepristone and misoprostol combination and misoprostol alone in first trimester MTP.

\section{MATERIALS AND METHODS}

The present study was carried out at Department of Obstetrics and Gynaecology at Government Thoothukudi 
Medical College, Thoothukudi, during 2013-2015. The purpose of the study is to compare the efficacy of mifepristone with misoprostol combination with vaginal misoprostol alone as a method of first trimester abortion.

During this period, 125 patients who attended the family planning clinic requesting first trimester termination of pregnancy were selected based on the inclusion and exclusion criteria given below. Out of 125 patients, 25 were randomly assigned to mifepristone with misoprostol (group A) and 100 to vaginal misoprostol (group B).

In this study, the patients fulfilling the inclusion criteria were confirmed pregnancy up to 9 weeks, single intrauterine live gestation, no previous surgery on the uterus, no other medical or surgical contraindication for the procedure, contraceptive failure, MTP for social eugenic causes. The exclusion criteria were women who are $>\mathrm{G} 3$, age $>35$, gestation age more than 9 weeks, missed, incomplete, inevitable abortion, patient with scarred uterus, suspected ectopic pregnancy, previous history of medical disorders like cardiac disease/diabetes/epilepsy/asthma, any previous attempts of terminating present pregnancy, pregnancies with IUD in situ.

All the women included were informed about the procedure and an informed consent was obtained. All of them were thoroughly investigated. Obstetric, medical, surgical, and menstrual history were recorded. General and obstetric examination, routine blood investigations, and USG pelvis was done.

\section{Mifepristone with Misoprostol (Group A)}

The mifepristone with misoprostol protocol is an outpatient procedure.

\section{Dosage Schedule}

Day 1: $200 \mathrm{mg}$ of mifepristone was given orally.

Day 3: $400 \mu \mathrm{g}$ of misoprostol kept vaginally and observed for 4-6 hrs. in OG dept.

Such of these women who did not expel within 4-6 hours after vaginal misoprostol were given the option of either going home and coming back on day 15 or admission in hospital. If abortion was not complete even after 15 days, it was considered as method failure and the patients were offered other methods of termination.

\section{Misoprostol (Group-B)}

100 patients were selected for vaginal misoprostol method of first trimester MTP and they were asked to empty the bladder and was asked to lie down in the dorsal position with knee semi-flexed and hip abducted. After cleaning and draping, a Sims speculum was introduced into vagina and posterior lip of cervix was caught with vulsellum $400 \mu \mathrm{g}$ of misoprostol was kept in posterior fornix and $5 \mathrm{~mL}$ of distilled water was instilled to dissolve the tablet to facilitate the absorption. Patient kept in the ward till expulsion was complete. Whenever necessary, check curettage was performed. If no expulsion occurred after $20-24$ hrs., it is considered as a failure and other interventions were offered. They were explained about the symptoms like nausea/vomiting/diarrhoea/abdominal cramps, headache, and bleeding.
The information collected were compiled methodically and analysed using the T-test- 2 tailed one sample test and chi-square test.

\section{RESULT AND ANALYSIS}

Most of the patients in both the groups were in the age group of 20-30 years (80\%). In Group A, $12 \%$ were above 30 years of age and $8 \%$ were less than 20 years. The difference is not statistically significant.

\begin{tabular}{|c|c|c|c|c|c|}
\hline \multirow{2}{*}{$\begin{array}{c}\text { Sl. } \\
\text { No. }\end{array}$} & \multirow{2}{*}{ Age } & \multicolumn{2}{|c|}{$\begin{array}{c}\text { Mifepristone + } \\
\text { Misoprostol }\end{array}$} & \multicolumn{2}{c|}{ Misoprostol } \\
\cline { 3 - 6 } & & $\begin{array}{c}\text { No. of } \\
\text { Cases }\end{array}$ & $\mathbf{\%}$ & $\begin{array}{c}\text { No. of } \\
\text { Cases }\end{array}$ & $\%$ \\
\hline 1. & $18-20$ & 2 & 8 & 10 & 13 \\
\hline 2. & $21-25$ & 10 & 40 & 46 & 43 \\
\hline 3. & $26-30$ & 10 & 40 & 26 & 25 \\
\hline 4. & $>30$ & 3 & 12 & 18 & 21 \\
\hline \multicolumn{6}{|c|}{ Table I } \\
\hline
\end{tabular}

Looking at the parity of women seeking MTP in the first trimester, it was found that more than $80 \%$ of patients were second gravida while $2 \%$ were unmarried. Parity is a major determinant of success rate in medical abortion.

\begin{tabular}{|c|c|c|c|c|c|}
\hline \multirow{2}{*}{$\begin{array}{c}\text { Sl. } \\
\text { No. }\end{array}$} & Gravidity & \multicolumn{2}{|c|}{$\begin{array}{c}\text { Mifepristone + } \\
\text { Misoprostol }\end{array}$} & \multicolumn{2}{c|}{ Misoprostol } \\
\cline { 3 - 6 } & $\begin{array}{c}\text { No. of } \\
\text { Cases }\end{array}$ & $\mathbf{\%}$ & $\begin{array}{c}\text { No. of } \\
\text { Cases }\end{array}$ & $\%$ \\
\hline 1. & $\begin{array}{c}\text { Unmarried } \\
\text { Pregnancy }\end{array}$ & 1 & 4 & 2 & 2 \\
\hline 2. & Primi & 4 & 16 & 18 & 18 \\
\hline 3. & G2 & 20 & 80 & 80 & 80 \\
\hline \multicolumn{5}{|c|}{ Table IA } \\
\hline
\end{tabular}

\begin{tabular}{|c|c|c|}
\hline Nulliparous & $\begin{array}{c}\text { Gestational Age } \\
\text { in Days } \\
<49 \\
50-56 \\
57-63 \\
>63\end{array}$ & $\begin{array}{c}\text { Complete } \\
\text { Abortion } \\
98.6 \% \\
98.3 \% \\
96.4 \% \\
11 \%\end{array}$ \\
\hline Parous & $\begin{array}{c}<49 \\
50-56 \\
57-63 \\
>63\end{array}$ & $\begin{array}{c}96.2 \% \\
93.1 \% \\
91.8 \% \\
10 \%\end{array}$ \\
\hline \multicolumn{3}{|c|}{ Table II } \\
\hline
\end{tabular}

Complete abortion in nulliparous women with gestational age of less than 49 days in 98.6\%; 50-56 days (98.3\%), 57-63 (96.4\%), >63 days the success rate was $11 \%$. The complete abortion in parous women were $96.2 \%$ in GA <49days, $93.1 \%$ in GA $50-56$ days, $91.8 \%$ in $57-63$ days, and $10 \%$ in GA >63 days on analysis. On comparing both the groups, in Group A, there was no incomplete or method failure in nulliparous women in contrast to group B where it was $6 \%$ and $3 \%$ respectively. In the parous women segment, there was $8 \%$ method failure in Group A than Group B (10\%). Similarly, high (31\%) incomplete abortion noted in Group B than Group B (0\%). 


\begin{tabular}{|c|c|c|c|c|c|c|c|c|c|}
\hline \multirow{3}{*}{ Sl. No. } & \multirow{3}{*}{ Characters } & \multicolumn{4}{|c|}{ Mifepristone + Misoprostol } & \multicolumn{4}{|c|}{ Misoprostol } \\
\hline & & \multicolumn{2}{|c|}{$\begin{array}{l}\text { Incomplete } \\
\text { Abortion }\end{array}$} & \multicolumn{2}{|c|}{ Method Failure } & \multicolumn{2}{|c|}{$\begin{array}{c}\text { Incomplete } \\
\text { Abortion }\end{array}$} & \multicolumn{2}{|c|}{ Method Failure } \\
\hline & & $\begin{array}{l}\text { No. of } \\
\text { Cases }\end{array}$ & $\%$ & $\begin{array}{l}\text { No. of } \\
\text { Cases }\end{array}$ & $\%$ & $\begin{array}{l}\text { No. of } \\
\text { Cases }\end{array}$ & $\%$ & $\begin{array}{l}\text { No. of } \\
\text { Cases }\end{array}$ & $\%$ \\
\hline 1. & Nulliparous & 0 & 0 & 0 & 0 & 6 & 6 & 3 & 3 \\
\hline 2. & Parous & 0 & 0 & 2 & 8 & 31 & 31 & 10 & 10 \\
\hline
\end{tabular}

Regarding parous women in Group A, there was only 8\% failure in method, in group B - 31\% were incomplete abortion and $10 \%$ method failure.

\begin{tabular}{|c|c|c|c|c|c|}
\hline \multirow{2}{*}{$\begin{array}{c}\text { Sl. } \\
\text { No. }\end{array}$} & \multirow{2}{*}{ Symptoms } & $\begin{array}{c}\text { Mifepristone + } \\
\text { Misoprostol }\end{array}$ & \multicolumn{2}{c|}{ Misoprostol } \\
\cline { 3 - 6 } & $\begin{array}{c}\text { No. of } \\
\text { Cases }\end{array}$ & $\mathbf{\%}$ & $\begin{array}{c}\text { No. of } \\
\text { Cases }\end{array}$ & $\%$ \\
\hline 1. & Symptom Free & 0 & 0 & 0 & 0 \\
\hline 2. & Abd/Ut. Cramps & 15 & 60 & 21 & 21 \\
\hline 3. & $\begin{array}{c}\text { Excessive } \\
\text { Bleeding }\end{array}$ & 7 & 28 & 44 & 44 \\
\hline 4. & Vomiting & 2 & 8 & 35 & 35 \\
\hline 5. & Dizziness & 1 & 4 & 0 & 0 \\
\hline \multicolumn{5}{|c|}{ Table IV } \\
\hline
\end{tabular}

On analysis of the symptoms, Group A $60 \%$ of patients had abdominal pain and uterine cramps; $28 \%$ of patients had excessive bleeding; $4 \%$ had dizziness; and $8 \%$ had vomiting.

In group B - 44\% of patients had excess bleeding; $35 \%$ of patients vomiting; and $21 \%$ of patients' abdominal and uterine cramps

\begin{tabular}{|c|c|c|c|}
\hline \multicolumn{2}{|c|}{ Characters } & \multirow{2}{*}{$\begin{array}{c}\begin{array}{c}\text { Mifepristone + } \\
\text { Misoprostol }\end{array} \\
4: 30 \mathrm{hrs} . \\
\end{array}$} & \multirow{2}{*}{$\begin{array}{c}\text { Misoprostol } \\
24 \mathrm{hrs} . \\
\end{array}$} \\
\hline & UMP & & \\
\hline \multirow[t]{3}{*}{ Parity } & G1 & $4: 00$ hrs. & 22:40 hrs. \\
\hline & G2 & 3:30 hrs. & 20:20 hrs. \\
\hline & $\begin{array}{l}<45 \\
\text { days }\end{array}$ & $3: 30$ hrs. & $24 \mathrm{hrs}$. \\
\hline \multirow[t]{2}{*}{$\begin{array}{c}\text { Gestational } \\
\text { Age } \\
\end{array}$} & $\begin{array}{c}>45-56 \\
\text { days }\end{array}$ & $4: 30-5$ hrs. & $22: 20 \mathrm{hrs}$. \\
\hline & $\begin{array}{l}>56 \\
\text { days }\end{array}$ & 4:00-4:30 hrs. & $22: 20 \mathrm{hrs}$ \\
\hline \multicolumn{4}{|c|}{ Table V: Induction Abortion Interval } \\
\hline
\end{tabular}

On analysing the induction-abortion interval time in context with parity and gestational age, the outcomes were analysed is both groups. In Group A, the induction-abortion interval time in primi and UMP were 4:30 hrs. and in Group B - it is $24 \mathrm{hrs}$. Patients with G2 in Group A, B - the induction abortion interval was 3:30 hrs., 20:20 hrs., respectively. On analysing GA of less than 45 days, the induction-abortion interval in group A, B was 3:30 hrs., 24 hrs., respectively. In GA $>56$ days, the induction-abortion interval in Group A, B was 4:00-4:30 hrs. and 22:20 hrs., respectively.

\section{DISCUSSION}

Most of the patients in both the groups were in the age group of $20-30$ years $(80 \%)$. In our study, $12 \%$ of women from Group A belong to the age of $>30$ and only $8 \%$ were below 20 years.
The difference is not statistically significant. Nulliparous and parous women with GA $>7$ weeks, the complete abortion rate was low. This is in concordance with the retrospective analysis of 3161 cases by Bartley et al.(6) The rational for this varied observation in different GA still remains unexplained. There is no variable significance in parity. Kahn in his metaanalysis finds the rate of complete abortion to $96 \%$ when period of amenorrhea is < 49 days, which declines to $85 \%$ when the gestational age is 57 days. (3)

The rate of complete abortion in patients with GA $>63$ days is found to be $94.5 \%$ and the same increased to $95.7 \%$ when additional dose of $800 \mu \mathrm{g}$ of misoprostol was kept vaginally.(7)

Spitz also conclude the same.(4) Our study also comply well with these studies. Complete abortion rate being $98.6 \%$ in nulliparous and $96.2 \%$ in parous women with GA $<49$ days. In Group A method, failure was 8\%, which required MVA technique. These results were similar to that of EL Rafacey et al who reported complete abortion rate to be $95 \%$ in vaginal administration than oral route.(1)

Peyron et al in 1993 in a study with mifepristone with misoprostol combination reported $96.9 \%$ complete abortion with $0.8 \%$ incomplete abortion, which is on par with our study.(2) Vomiting was seen in $8 \%$ of our patients unlike the study of Cabeza et al in 1998 where it was $15 \%$.(8) Spitz reports $100 \%$ bleeding in his study in contrast to only $28 \%$ of our patients had excessive bleeding. Both vomiting and bleeding were more when misoprostol alone was used for MTP (35\% and 44\% respectively). $60 \%$ of women from our study experienced pain, which was similar to the rate of pain in Cabaza et al, Peyron et al has shown in a study that success rate of misoprostol is more effective when it is used in combination with mifepristone than when used alone. All these studies including our study confirmed that complete abortion rate in early pregnancy was more with group $\mathrm{A}$. Similarly, meta-analysis of 2000 patients revealed that the rate of incomplete abortion was more in misoprostol group.

This difference is statistically significant. In El Rafecy et al, $93 \%$ of abortion occurred within 4 hrs. of vaginal misoprostol administration in mifepristone with misoprostol and 78\% occurred within $4 \mathrm{hrs}$. if misoprostol was administered orally. Our study also reveals that induction-abortion interval was only 4-5 hrs. in vaginal administration of misoprostol similar to EL Rafecy et al. The induction-abortion interval in Group B was 23-24 hrs. similar to study by Blanchard and others. $(5,9$, Thus, the combined regimen has more rate of complete abortion with less induction abortion interval than when misoprostol alone was used.

\section{SUMMARY}

This is a comparative study of medical methods for first trimester abortion conducted at Department of Obstetrics and Gynaecology at Government Thoothukudi Medical College, Thoothukudi. 
- Total no. of patients-125.

- No. of women who were given mifepristone and misoprostol combination- 25 .

- $\quad$ No. of misoprostol alone-100.

\section{Following were the Observations of this Study}

1. Most of the patients were in the age group 21-30 and parous.

2. $4 \%$ of patients were unmarried who responded well for medical methods.

3. $50 \%$ patients had various symptoms in both groups.

4. Expulsion was complete in the mifepristone/misoprostol group and no women needing check curettage for combination of complete abortion. However, in 2 women, there was no response and their pregnancy was terminated by MVA. On the other hand, $50 \%$ of women in the misoprostol alone group had to have curettage for completing the abortion process.

5. Induction-abortion time is less in patients with mifepristone/misoprostol than misoprostol alone (4-5 hours vs. 20-22 hrs. respectively).

6. None of the patients needed blood transfusion or volume expanders.

7. None of the patients had delayed bleeding after 45 days.

8. Misoprostol is less expensive and efficacious. However, induction-abortion interval is prolonged than mifepristone/misoprostol combination.

9. Though mifepristone is more expensive, the high complete abortion rate and expulsion 4-5 hours of misoprostol administration makes it a preferred method were cost is not restraining factor.

\section{CONCLUSION}

From our study result, it can be concluded that mifepristone with misoprostol combination is an effective and ideal outpatient procedure for early MTP. Complete abortion rate is high with this combination. Similarly, the induction abortion interval with this method is also less. Other associated complications are also less. The only confounding factor is the cost involved, which is about 20 times that of misoprostol alone. This makes the mifepristone with misoprostol combination the most-effective method for the first trimester abortion.

\section{REFERENCES}

1. El-Refaey H, Rajasekar D, Abdalla M, et al. Induction of abortion with mifepristone (ru486) and oral or vaginal misoprostol. New Eng J Med 1995;332(15):983-7.

2. Peyron R, Aubeny E, Targosz V, et al. Early termination of pregnancy with mifepristone (ru486) and the orally active prostaglandin misoprostol. New Eng J Med 1993;328(21):1509-13.

3. Kahn J, Becke BG, Maclsaa L, et al. The efficacy of medical abortion: a meta-analysis. Contraception 2000;61(1):2940.

4. Spitz IM, Bardin CW, Benton L, et al. Early pregnancy termination with mifepristone and misoprostol in the United States. New Eng J Med 1998;338(18):1241-7.

5. Schaff EA, Eisinger SH, Stadaluis LS, et al. Low-dose mifepristone $200 \mathrm{mg}$ and vaginal misoprostol for abortion. Contraception 1999;59(1):1-6.

6. Bartleya J, Tongb S, Everingtona D, et al. Parity is a major determinant of success rate in medical abortion: a retrospective analysis of 3161 consecutive cases of early medical abortion treated with reduced doses of mifepristone and vaginal gemeprost. Contraception 2000;62(6):297-303.

7. Ashok PW, Templeton A, Wagaarachchi PT, et al. Factors affecting the outcome of early medical abortion: a review of 4132 consecutive cases. BJOG 2002;109(11):1281-9.

8. Blanchard K, Winikoff B, Coyaji K, et al. Misoprostol alone-a new method of medical abortion? Journal of the American Medical Women's Association 2000;55(Suppl3):189-90.

9. Cabezas E. Medical versus surgical abortion. International Journal of Gynaecology and Obstetrics 1998;63(Suppl1):S141-6. 